\title{
A DIVERSIDADE SEXUAL PERMEADA PELA TEORIA DAS REPRESENTAÇÕES SOCIAIS: UMA REVISÃO NARRATIVA
}

\author{
Vanessa Lima Blaudt ROCHA ${ }^{1}$ \\ Mary RANGEL ${ }^{2}$
}

Resumo: Este artigo se constitui em uma revisão narrativa e tem como objetivo analisar a questão da diversidade sexual mediada pela teoria das representações sociais. Buscase traçar o panorama da produção acadêmica alusiva à temática bem como apreender aproximações e singularidades nas investigações dos diferentes autores. A pesquisa da literatura pertinente ao assunto ocorreu na base de dados Scientific Eletronic Library Online (Scielo), no período delimitado entre 2000 e 2015, em artigos produzidos no Brasil. No curso do texto, subsequente à análise descritiva, foi feita a análise integrativa das pesquisas, que demostrou, mormente, representações arraigadas de significações negativas. Destacam-se duas aproximações nos estudos: a problematização do preconceito e da natureza da homossexualidade. Quanto às singularidades, a raridade de investigações no domínio escolar realça-se. Outrossim, os estudos mostraram-se insuficientes e escassos, logo, o aprofundamento das investigações dissemina-se como um caminho fértil para a superação e a desconstrução de práticas impregnadas de intolerância e de repúdio a padrões não hegemônicos.

Palavras-chave: Representações sociais. Diversidade sexual. Educação.

\section{Introdução}

A partir das últimas décadas do século $\mathrm{XX}$, mudanças significativas nas concepções alusivas à sexualidade e ao gênero ocorreram. Caetano (2013) destaca, nesse período, o movimento feminista, que, por sua diversidade de reflexões e práticas, inseriu as diferenças entres os sexos nas investigações acadêmicas e nas políticas públicas ao incorporar o conceito de gênero. A emersão da categoria do gênero possibilitou a problematização dos equívocos acerca do sexo e a produção de conhecimento frente aos saberes hegemônicos que desmantelavam direitos à cidadania (CAETANO, 2013).

Presentemente, gênero e sexualidade, não obstante afinidades e significados diversos, têm introduzido indagações concernentes às identidades e à visibilidade de

\footnotetext{
${ }^{1}$ Mestranda em Educação. UFF - Universidade Federal Fluminense. Faculdade de Educação - PósGraduação em Educação. Niterói - RJ - Brasil. 24210-201 - valb.edfisica@gmail.com

${ }^{2}$ UFF - Universidade Federal Fluminense. Faculdade de Educação - Pós-Graduação em Educação. UERJ - Universidade do Estado do Rio de Janeiro. Faculdade de Ciências Médicas. Niterói - RJ - Brasil. 24020-006 - mary.rangel@lasalle.org.br
} 
grupos definidos como os "outros", ou seja, aqueles que não partilham os atributos tidos por comuns. Dessa forma, os sujeitos considerados estranhos podem-se sentir desiguais por não se assemelharem aos padrões aceitos como normais (RANGEL, 2013).

Realça-se, então, a relevância do debate acerca das sexualidades - “[...] heterossexualidades, homossexualidades, lesbianidades, transexualidades e outras formas de sexualidade que ainda estão por ser construídas" (TORRES, 2010, p. 10). A diversidade sexual, alertam Nardi e Quartiero (2012), revela-se um denominador comum relacionado a todos os que não são heterossexuais. Assim, a heterossexualidade exclui-se do termo diversidade sexual, pois aquilo que é (pretensiosamente) normal e usual não precisa ser nominado ou categorizado.

Ao categorizarem-se objetos ou pessoas, imputam-se rótulos e identidades não usuais ou não familiares, aflorando, por conseguinte, ações estigmatizantes e excludentes. Nessa perspectiva, formam-se as representações dos outros que não se ajustam aos padrões culturais dos grupos mais numerosos, sendo considerados estranhos, como os que não correspondem à padronização heterossexual.

Destarte, as representações que categorizam valores e posições sociais desvelam-se “[...] aportes de pesquisas interessadas em contribuir para a sua compreensão e, sobretudo, em apontar superações necessárias a que se desconstruam preconceitos distantes do real, que se sustentam e disseminam por meio de julgamentos e discursos equivocados [...]" (RANGEL, 2013, p. 22).

\section{Objetivos}

Este estudo visa a identificar e a descrever, mediante revisão narrativa, o panorama da produção acadêmica nacional pertinente à diversidade sexual na perspectiva da teoria das representações sociais, bem como apreender aproximações e singularidades das visões dos diferentes autores e suas vertentes teóricas, delineando o atual estado do conhecimento.

\section{O processo de busca e suas limitações}

A metodologia do estudo proposto caracteriza-se como uma revisão de literatura narrativa. Nas palavras de Rother (2007, p. v), “[...] os artigos de revisão narrativa são publicações amplas apropriadas para descrever e discutir o desenvolvimento ou o 'estado da arte' de um determinado assunto, sob ponto de vista teórico ou conceitual." São textos que propiciam a análise crítica do autor sobre determinado assunto. 
Sendo assim, a revisão de literatura ocorreu na base de dados Scielo (Scientific Electronic Library Online), na qual foram encontrados artigos segundo os critérios de inclusão definidos para a presente revisão narrativa: artigos produzidos no Brasil, no período compreendido entre 2000 e 2015; e artigos publicados cujo referencial teórico coadunasse a teoria das representações e a diversidade sexual. Os descritores utilizados foram os seguintes: representações sociais e diversidade sexual; representações sociais e homossexuais; representações sociais e homossexualidade. Os resumos obtidos no banco de dados, após a inserção dos descritores, foram comparados entre si para a supressão de artigos repetidos. Posteriormente, alguns trabalhos foram excluídos quando da leitura dos resumos e dos artigos na íntegra por não se enquadrarem aos critérios de inclusão propostos. Ao final do processo de busca, verificou-se que somente sete artigos se mostraram pertinentes à temática proposta.

Ainda no que toca ao aspecto metodológico, uma análise descritiva sintética dos artigos foi realizada para posterior análise integrativa das principais aproximações e singularidades evidenciadas relativas à contextualização social, aos objetivos, aos campos de investigações e aos resultados.

\section{Revisão descritiva}

Inicialmente, o estudo abordado será o desenvolvido por Lacerda, Pereira e Camino (2002), denominado "Um estudo sobre as formas de preconceito contra homossexuais na perspectiva das representações sociais". Seu objetivo era averiguar o preconceito de universitários da cidade de João Pessoa contra homossexuais a partir de duas dimensões: a rejeição à intimidade e a expressão de emoções positivas e negativas. Ademais, investigou-se a relação das formas de preconceito com as explicações sobre a homossexualidade.

A investigação preliminar perpassou pela natureza do preconceito e suas perspectivas e apontou um refinamento na discriminação devido à indesejabilidade social do preconceito. Para o estudo do preconceito contra homossexuais, adaptou-se a tipologia proposta por Pettigrew e Meertens (1995), que assinala três formas de relações raciais: preconceito flagrante, preconceito sutil e igualitarismo.

O levantamento de dados partiu de um questionário destinado a 220 estudantes universitários contendo o tipo de curso, sexo, religião e as seguintes escalas: rejeição à intimidade, expressão emocional e explicações da homossexualidade. A análise das explicações da homossexualidade relacionada ao preconceito contra homossexuais foi 
realizada com o escopo de "[...] classificar as diversas explicações em cinco possíveis modelos explicativos da homossexualidade: biológico, psicológico, psicossocial, religioso e ético-moral [...]" (LACERDA; PEREIRA; CAMINO, 2002, p. 169). O tratamento dos dados obtidos deu-se através do modelo de análise quantitativa das representações sociais.

Os resultados oportunizaram a categorização dos estudantes em três grupos de indivíduos, quais sejam: preconceituosos flagrantes, preconceituosos sutis e não preconceituosos. A análise da ancoragem social do tipo de preconceito dos estudantes

[...] mostrou que os preconceituosos flagrantes se opuseram às explicações psicossociais (próprias das mulheres e dos estudantes de psicologia) e aderiram mais fortemente às explicações ético-morais e religiosas (próprias dos estudantes de engenharia). Os não preconceituosos estudam psicologia e aderem às explicações psicossociológicas. Já os preconceituosos sutis explicaram a homossexualidade a partir de causas biológicas e psicológicas, próprias dos estudantes de medicina e das mulheres. (LACERDA; PEREIRA; CAMINO, 2002, p. 165).

Os resultados, ainda, evidenciaram que, do total de estudantes analisados, mais de três quartos foram classificados, na mesma proporção, como preconceituosos flagrante e sutil. Segundo os autores, esse dado ratifica o fato de o Brasil ter um dos maiores índices mundiais de assassinatos de homossexuais.

Com enfoque temático similar, Scardua e Souza Filho (2006) discutiram "O debate sobre a homossexualidade mediado por representações sociais: perspectivas homossexuais e heterossexuais" e investigaram o preconceito de estudantes universitários da região metropolitana do Rio de Janeiro, consoante a orientação sexual em homossexuais e heterossexuais, masculinos e femininos.

O levantamento de dados foi realizado através de um questionário, aplicado a 350 universitários, que contemplava uma questão de associação livre sobre a palavra homossexualidade e outra, aberta, alusiva às suas prováveis causas. As respostas dos participantes foram examinadas através da análise de conteúdo temática e revelaram distanciamentos e aproximações dos grupos pesquisados e representações contraditórias entre si.

Os homens homossexuais procuraram justificar/legitimar publicamente (direitos, liberdade) a homossexualidade com o argumento/representação de que ela é incontrolável/natural, enquanto as mulheres homossexuais preferiram construir e aperfeiçoar contratos de interação no plano interpessoal (família, namoro) para obter 
reconhecimento social. Já os homens e mulheres heterossexuais, referindo-se muito à normatização e outros conteúdos que reforçam as convenções sociais, indicaram menos possibilidade de reconhecimento da homossexualidade. (SCARDUA; SOUZA FILHO, 2006, p. 482).

Focalizando, ainda, a esfera do ensino superior, Araújo et al. (2007) problematizaram a "Adoção de crianças por casais homoafetivos: um estudo comparativo entre universitários de direito e de psicologia", com o escopo de apreender, analisar e comparar as representações desses estudantes.

$\mathrm{Na}$ coleta de dados, realizada por intermédio de um questionário, 104 universitários responderam aos itens relativos às suas identificações sociodemográficas e à seguinte pergunta: Qual a sua opinião sobre a adoção de crianças por casais homossexuais? O tratamento dos dados deu-se por meio da análise temática de conteúdo.

Identificou-se, nos resultados, a similitude das representações sociais contrárias à adoção no contexto da homossexualidade dos universitários de ambos os cursos. Porém, de forma contraditória, merece destaque o fato de os estudantes narrarem que a adoção por casais homoafetivos denota uma atitude inclusiva, uma vez que se prima, no processo de adoção, pelo bem-estar da criança, em detrimento da orientação sexual dos adotantes.

Dessa forma, pode-se inferir que o preconceito flagrante enraizado entre os jovens universitários frente à adoção de crianças por casais homoafetivos faz-se presente; todavia, uma nova aparência desse preconceito anuncia-se com a sutilidade das atitudes discriminatórias.

O preconceito destaca-se, novamente, em Pereira et al. (2011), no estudo do "Preconceito contra homossexuais e representações sociais da homossexualidade em seminaristas católicos e evangélicos". Os autores realizaram estudo correlacional que intentou responder a questões obscuras no tocante às crenças e atitudes de grupos religiosos em relação aos homossexuais e à natureza da homossexualidade.

O levantamento de dados constou de questionário aplicado a 374 estudantes de teologia que, além de conter questões relativas ao sexo, à idade, ao tempo de curso e ao grau de religiosidade, apresentou medidas do preconceito e uma medida de crenças sobre a natureza da homossexualidade. O preconceito foi medido por meio de duas escalas: rejeição a relações de proximidade e expressões de emoções. 
Mediante o modelo de análise quantitativa das representações sociais, as informações obtidas desvelaram que os grupos religiosos manifestam suas atitudes em relação aos homossexuais em forma de preconceito flagrante ou sutil, ratificando um preconceito generalizado.

Os resultados evidenciaram, ainda, que o tipo de preconceito é diferente em cada tipo de seminário - os evangélicos exprimem o preconceito de forma mais flagrante; os católicos, de forma mais sutil - e dependente das crenças sobre a natureza da homossexualidade - entre evangélicos predomina uma representação caracterizada pela crença na natureza religiosa, ético-moral e psicológica; nos seminários católicos, predomina a crença na natureza psicológica da homossexualidade.

O preconceito sutil está relacionado com a crença numa natureza biológica e psicossocial e com a descrença numa representação éticomoral da homossexualidade. O preconceito flagrante está relacionado com a descrença na natureza biológica e psicossocial e com uma representação ético-moral. A hipótese de que as representações sociais sobre a natureza dos grupos minoritários estão na base do preconceito e da discriminação é corroborada. (PEREIRA et al., 2011, p. 73).

Em perspectiva similar de averiguar as representações sociais sobre a natureza da homossexualidade e as relações de preconceito bem como o apoio a políticas discriminatórias contra homossexuais, Pereira et al. (2013) desenvolveram um estudo a partir do seguinte tema: "O papel de representações sociais sobre a natureza da homossexualidade na oposição ao casamento civil e à adoção por famílias homoafetivas".

$\mathrm{O}$ foco de suas considerações fundamentou-se na ideia de que, se as representações são fatores essenciais ao apoio a políticas discriminatórias contra homossexuais, as relações entre as crenças sobre a homossexualidade e a discriminação contra esse grupo social devem ser mediadas pelo preconceito flagrante contra homossexuais.

Um questionário foi respondido por 297 estudantes concluintes dos cursos de Psicologia e, para o tratamento das informações obtidas, utilizou-se como fundamento teórico o modelo de análise quantitativa das representações sociais.

Após a análise das relações entre as representações da homossexualidade, do preconceito e da discriminação contra os homossexuais, alguns resultados emergiram: 
políticas discriminatórias contra os homossexuais, nomeadamente a oposição ao casamento e à adoção de crianças por casais homoafetivos. A crença na natureza cultural da homossexualidade prediz o menor apoio a essas políticas. As relações verificadas são mediadas pelo preconceito flagrante contra homossexuais. (PEREIRA et al., 2013, p. 79).

Os resultados apontaram que o preconceito pode ser o mecanismo psicológico por meio do qual as representações sociais da natureza dos grupos sociais potencializam a discriminação. "Esses resultados podem ser compreendidos à luz da teoria das RS, principalmente devido ao fato de as representações resultarem da transformação de conceitos e relações elaborados no âmbito institucional e transformados em saber de senso comum [...]" (PEREIRA et al., 2011, p. 86). Tal afirmativa corrobora com o argumento segundo o qual o conhecimento, no âmbito científico, instiga a formação de crenças e teorias do senso comum que permeiam as relações intergrupais.

Os autores propuseram, por fim, que a implementação de políticas públicas com o escopo de problematizar a questão do preconceito e de promover a inclusão dos homossexuais deve coadunar-se com as teorias de senso comum sobre a natureza da homossexualidade.

Martins-Silva et al. (2012) adentraram ao âmbito escolar com o intuito de investigar as concepções de alunos do ensino fundamental de escolas particulares e públicas referentes à homossexualidade: "Adolescentes e homossexualidade: representações sociais e identidade social”. Para tanto, focalizaram a teoria da identidade social e a teoria das representações sociais, isso porque "[...] as duas pressupõem uma questão essencial: a importância do contexto social na compreensão de si, do outro e do mundo.” (MARTINS-SILVA et al., 2012, p. 482).

A pesquisa qualitativa utilizou, no tratamento dos dados, um questionário endereçado a 283 estudantes, constituído de dados pessoais e de perguntas a respeito da homossexualidade. As informações obtidas foram analisadas por intermédio do software Alceste - Análise Lexical Contextual de um Conjunto de Segmentos de Texto.

Identificaram-se, através dos resultados, discursos diferentes alusivos aos homossexuais: discurso agressivo e o que preconiza respeito. Os discursos revelaram a disparidade entre a escola particular e a escola pública quando da análise separada desses grupos. A primeira manifestou o discurso ancorado na lógica bidimensional de gênero; a segunda, na agressividade. Dessa forma, os resultados mostraram elementos 
positivos e negativos na representação social da homossexualidade, estando o seu processo de formação associado ao processo de formação identitário.

Em relação à configuração da representação social, restou demonstrado que esta

[...] se relaciona a medo provocado por objetos sociais diferentes do que é considerado padrão; tentativa de retomar o sentido de ordem e controle sobre o mundo; valores e crenças presentes na história da sociedade; e posição social dos grupos sociais e ganhos que podem advir da relação intergrupal. (MARTINS-SILVA et al., 2012, p. 474).

Desviando-se do âmbito educacional, Figueiredo, Cavedon e Silva (2013) propuseram a seguinte investigação: “A desvalorização de grupos socais no espaço comum de pequenas organizações: um estudo sobre representações sociais em um centro comercial". Mediante observação participante e entrevistas não estruturadas, articuladas a partir de análise etnográfica, os autores objetivaram compreender a construção de sentidos de valoração negativa que depreciam grupos sociais específicos.

A motivação do estudo assenta-se na transformação dos grupos sociais que frequentavam um centro comercial. Os visitantes que, inicialmente, eram constituídos de um grupo da classe intelectualizada e de outro composto por homossexuais maduros e com elevado poder aquisitivo, posteriormente, compuseram-se de homossexuais jovens e com menor poder aquisitivo. A diversidade dos grupos frequentadores resultou no potencial negativo das representações circulantes.

Após o tratamento das informações obtidas, dois grupos emergiram: bons frequentadores e maus frequentadores, os últimos vinculados à juventude e à homossexualidade. "A relação entre seus membros e as pessoas nas organizações leva à construção de representações sociais por vezes carregadas de significações negativas com impactos nas relações sociais e organizacionais estabelecidas naquele locus" (FIGUEIREDO; CAVEDON; SILVA, 2013, p. 55).

Realçou-se a estigmatização sofrida por pessoas em certos espaços com o objetivo único de bani-las por meio de regras excludentes válidas. $\mathrm{O}$ indivíduo, para usufruir daquele espaço, precisa moldar-se à identidade social tolerada. "No caso dos homossexuais jovens, a identidade social da qual eles se aproximam se diferencia da desejada pelos membros organizacionais no espaço do centro comercial" (FIGUEIREDO; CAVEDON; SILVA, 2013, p. 68). 
Posterior à análise descritiva sintética dos artigos, a revisão integrativa faz-se presente, como forma de apontar aproximações e singularidades nas visões dos autores e suas vertentes teóricas.

\section{Análise integrativa: aproximações e singularidades nas perspectivas dos autores}

A análise integrativa dos artigos desenvolve-se com o escopo de identificar pontos comuns e distanciamentos prevalentes nas evidências disponíveis. A presente análise visa a elencar os seguintes quesitos: contextualização social, objetivos, campo de investigação e resultados.

A contextualização social elucida-se a partir de proposições que assinalam a marginalização sofrida pelas minorias sexuais, apesar de reconhecidos avanços assegurados na legislação em vários países e da proliferação de espaços de tolerância homossexual. Os estudos que abarcam esse grupo social se mostram escassos, e a problematização das diferentes formas de preconceito relacionadas à homofobia e à identificação do modo como a homossexualidade é concebida revelam-se caminhos promissores contra a discriminação. Nesse cenário, as representações sociais são instrumentos idôneos para as explicações do conhecimento social elaborado e difundido a respeito de indivíduos e grupos que não se ajustam aos padrões culturais hegemônicos, como as minorias sexuais.

Dos objetivos analisados, três tinham como alvo o levantamento do preconceito e o seu encadeamento com variáveis distintas, como a natureza da homossexualidade e o apoio a políticas discriminatórias. Dois pretenderam desvendar as concepções da homossexualidade na perspectiva da teoria das representações. Os demais objetivos apontaram para as seguintes singularidades: identificar unicamente as representações sociais sobre a adoção de crianças por casais homoafetivos e compreender a construção de sentidos depreciativos atribuídos a determinados grupos sociais.

Quanto ao campo de investigações, constatou-se a prevalência de estudos realizados no domínio educacional. Especificamente, o ensino superior totaliza quatro artigos. As singularidades apontam para os seguintes domínios: escolas pública e privada; seminários religiosos; e centro comercial.

Os resultados dos artigos, que visaram ao levantamento do preconceito relacionado às representações sociais acerca da natureza da homossexualidade e às políticas discriminatórias, mostram que as explicações ético-morais e religiosas da homossexualidade se correlacionam com preconceito flagrante, e com menor apoio à 
adoção e à união civil por famílias homoafetivas. O preconceito flagrante, ainda, opõese às explicações psicossociais da homossexualidade. Às crenças biológicas atrelam-se os preconceituosos sutis. As explicações culturais da homossexualidade predizem menor apoio às políticas discriminatórias.

Os demais resultados ilustram representações sociais arraigadas de significações negativas. Nessa perspectiva, os seguintes conteúdos emergem: menor possibilidade de reconhecimento da homossexualidade por parte dos heterossexuais; posicionamentos contrários à adoção de crianças por casais homoafetivos, justificados por questões morais; discursos agressivos, exemplificados por termos, tais como: boiola, viado (sic), sem-vergonha etc.; e classificações depreciativas que apontam os homossexuais como maus frequentadores de determinada localidade.

A convergência de representações negativas, então, torna-se manifesta. No entanto, ainda que de forma escassa, algumas evidências positivas destacam-se, quando da identificação de representações tendentes à aceitação da homossexualidade como uma forma de existência, à necessidade do respeito às diferenças sexual e à sutilidade de atitudes discriminatórias, revelando uma nova aparência do preconceito.

\section{Considerações finais}

Neste artigo, intentou-se traçar o panorama atual relativo à diversidade sexual na perspectiva da teoria das representações e conhecer a visão dos autores que se debruçam sobre o tema.

Embora tenham sido encontrados poucos artigos sobre o assunto proposto, destacaram-se, de maneira mais pronunciada, duas aproximações que motivaram as investigações discutidas: a problematização do preconceito, perpassando por sua natureza e por suas formas de expressão, e a identificação das representações sociais, especificamente, sobre a natureza dos grupos sociais. Referida constatação fundamentase na crença de que o estudo das representações sociais que as pessoas têm feito da homossexualidade permitirá conceber a existência de diversas formas de preconceito.

Ademais, quer-se realçar a singularidade de proposições na esfera escolar. A escola é um espaço público e, portanto, deve oportunizar aprendizagens fundamentadas no diálogo com as diferenças e nas regras de convívio repletas de tolerância. A instituição escolar deve adentrar ao embate dos processos excludentes, cujo propósito se assenta na marginalização de identidades não padronizadas. 
Finalmente, assevera-se que os estudos alusivos às diversidades sexuais na perspectiva das representações sociais desvelaram um referencial teórico ainda em construção e, portanto, carente de investigações. $\mathrm{O}$ aprofundamento das pesquisas tornase um caminho fértil para a superação e a desconstrução de práticas impregnadas de intolerância e de repúdio a padrões não hegemônicos.

\title{
Agradecimentos
}

Os autores agradecem à Capes e ao CNPQ o apoio e os recursos financeiros recebidos para o desenvolvimento deste trabalho.

\section{THE SEXUAL DIVERSITY PERMEATED BY THE THEORY OF SOCIAL REPRESENTATIONS: A NARRATIVE REVISION}

\begin{abstract}
This article constitutes a narrative review and aims to analyze the issue of sexual diversity mediated by the Social Representation Theory. The aim is to trace the panorama of academic production alluding to the theme and apprehend approaches and singularities in the investigations of different authors. A research of the literature on the subject was conducted at the Scielo's database in the period delimited between 2000 and 2015 through articles produced in Brazil. Throughout the course of the text, following the descriptive analysis, the integrative analysis of research, in particular, demonstrated rooted representations of negative meanings. Noteworthy are two approaches in the studies: the questioning of prejudice and homosexuality's nature. As for the singularities, the lack of investigations in the school sector stands out. Furthermore, the studies have shown to be insufficient and scarce, so further investigations could possibly be the way to overcome the deconstruction of impregnated practices of intolerance and rejection of non-hegemonic standards.
\end{abstract}

Key words: Social representations. Sexual diversity. Education.

\section{REFERÊNCIAS}

ARAÚJO, L. F. de et al. Adoção de crianças por casais homoafetivos: um estudo comparativo entre universitários de direito e de psicologia. Psicologia \& Sociedade, São Paulo, v. 19, n. 2, p. 95-102, 2007.

CAETANO, M. Gênero e sexualidade: diálogos e conflitos. In: RANGEL, M. (Org.). A escola diante da diversidade. Rio de Janeiro: Walk, 2013. p.35-68.

FIGUEIREDO, M. D. de.; CAVEDON, N. R.; SILVA, A. R. L. de. A desvalorização de grupos socais no espaço comum de pequenas organizações: um estudo sobre representações sociais em um centro comercial. Organizações \& Sociedade, Salvador, v. 20, n. 64, p. 55-73, 2013. 
LACERDA, M.; PEREIRA, C.; CAMINO, L. Um estudo sobre as formas de preconceito contra homossexuais na perspectiva das representações sociais. Psicologia: Reflexão e Crítica, Porto Alegre, v. 15, n. 1, p. 165-178, 2002.

MARTINS-SILVA, P. O. et al.. Adolescentes e homossexualidade: representações sociais e identidade social. Cadernos de Pesquisa, São Paulo, v. 42, n. 146, p. 474-493, 2012.

NARDI, H.; QUARTIERO, E. Educando para a diversidade: desafiando a moral sexual e construindo estratégias de combate à discriminação no cotidiano escolar. Sexualidad, Salud y Sociedad: Revista Latinoamericana, Rio de Janeiro, n. 11, p. 59-87, 2012.

PEREIRA, C. R. et al. O papel de representações sociais sobre a natureza da homossexualidade na oposição ao casamento civil e à adoção por famílias homoafetivas. Psicologia: Teoria e Pesquisa, Brasília, v. 29, n. 1, p. 79-89, 2013.

PEREIRA, C. R. et al. Preconceito contra homossexuais e representações sociais da homossexualidade em seminaristas católicos e evangélicos. Psicologia: Teoria e Pesquisa, Brasília, v. 27, n. 1, p. 73-82, 2011.

PETTIGREW, T. F.; MEERTENS, R. W. Subtle and blatant prejudice in Western Europe. European Journal of Social Psychology, [S.1.], v. 25, p. 57-75, 1995.

RANGEL, M. Desigualdades e seus efeitos na autorrepresentação. In: RANGEL, M. (org.). A escola diante da diversidade. Rio de Janeiro: Walk, 2013. p. 15-34.

ROTHER, E. T. Revisão sistemática X revisão narrativa. Acta Paulista de Enfermagem, São Paulo, v. 20, n. 2, p. v-vi, 2007.

SCARDUA, A.; SOUZA FILHO, E. A. O debate sobre a homossexualidade mediado por representações sociais: perspectivas homossexuais e heterossexuais. Psicologia: Reflexão e Crítica, Porto Alegre, v. 19, n. 3, p. 482-490, 2006.

TORRES, M. A. A diversidade sexual na educação e os direitos de cidadania LGBT na escola. 2. ed. Belo Horizonte: Autêntica; Ouro Preto: Ed. da UFOP, 2010. 